
cultural y científica entre Perú y Francia

\title{
El país de Montaigne y nosotros
}

Le pays de Montaigne et nous

The country of Montaigne and us

\section{Hugo Neira}

\section{OpenEdition \\ Journals}

Edición electrónica

URL: http://journals.openedition.org/bifea/4431

DOI: $10.4000 /$ bifea.4431

ISSN: 2076-5827

Editor

Institut Français d'Études Andines

Edición impresa

Fecha de publicación: 8 mayo 2007

Paginación: 5-17

ISSN: 0303-7495

Referencia electrónica

Hugo Neira, «El país de Montaigne y nosotros », Bulletin de l'Institut français d'études andines [En línea], 36 (1) | 2007, Publicado el 08 mayo 2007, consultado el 01 diciembre 2020. URL : http:// journals.openedition.org/bifea/4431; DOI : https://doi.org/10.4000/bifea.4431

\section{(c) $(1)(8)$}

Les contenus du Bulletin de l'Institut français d'études andines sont mis à disposition selon les termes de la licence Creative Commons Attribution - Pas d'Utilisation Commerciale - Pas de Modification 4.0 International. 


\title{
El país de Montaigne y nosotros
}

\author{
Hugo Neira*
}

\section{Resumen}

El artículo explora la relación entre las dos culturas, la francesa y la peruana. Luego de evocar los intelectuales franceses del siglo XX —Malraux, Sartre, Camus_ el autor divide su trabajo en dos partes. En la primera, «La aventura francesa, la esfinge del Perú» señala que desde el XVI, desde la Conquista, desde Nouvelles certaines des isles du Pérou, publicada en 1534, en Lyon, el lejano Perú no deja de interesar: Montaigne, enciclopedistas y viajeros franceses, Feuillée, Frézier, Radiguet. Aún madame de Graffiny, o Parmentier, introductor de la papa, tienen su sitio en este vasto cuadro de historia cultural. La segunda parte es para señalar el papel jugado por modas y tendencias intelectuales en la conciencia de sí de los peruanos. Lamenta, al final, la sustitución norteamericana a nivel de la educación, los métodos que han desaparecido y la calidad de la prosa de ideas.

Palabras clave: descubrimiento de América, conquista, cronistas, literatura de viajeros, intelectuales, historia de las ideas, modas, comparatismo, comparativismo

\section{Le pays de Montaigne et nous}

\section{Résumé}

L'article étudie le lien entre deux cultures, la française et la péruvienne. Après avoir évoqué les intellectuels français du XXe siècle — Malraux, Sartre, Camus —, I'auteur divise son travail en deux parties. Dans la première, «L'aventure française, le sphinx du Pérou », il signale que depuis le $\mathrm{XVI}^{\mathrm{e}}$ siècle, depuis la Conquête, depuis la publication de Nouvelles certaines des isles du Pérou en 1534 à Lyon, le lointain Pérou n'a jamais cessé de susciter intérêt : Montaigne, les encyclopédistes et voyageurs français - Feuillée, Frézier, Radiguet - . Même Madame de Graffiny, ou Parmentier, l'introducteur de la pomme-de-terre, ont leur place dans ce vaste tableau de I'histoire culturelle. La seconde partie signale le rôle joué par les modes et les tendances intellectuelles dans la conscience de soi des Péruviens. L'auteur regrette, à la fin de son article, l'influence américaine qui a supplanté l'influence française au niveau de l'Éducation (I'enseignement des méthodes qui a disparu) et de la qualité de la prose universitaire.

Mots clés : découverte de l'Amérique, Conquête, chroniqueurs, littérature de voyageurs, intellectuels, histoire des idées, modes, comparatisme, comparativisme 


\title{
The country of Montaigne and us
}

\begin{abstract}
The article deals with the relationship between the French and Peruvian cultures. After recalling the 20th century's French intellectuals - Malraux, Sartre, Camus - the author splits his work into two parts. In the first one, «The French adventure, Peru's sphinx», he underlines that since the Conquest, since Nouvelles certaines des isles du Pérou, published in 1534 in Lyon, the interest in the faraway Peru has never faded: Montaigne, French encyclopedists and travellers, Feuillee, Frézier, Radiguet. Even madame de Graffiny, or Parmentier, who introduced the potato, feature in this major picture of cultural history. The second part focuses on the role that intellectual fashions and trends play in the self-image of Peruvians. In the end he regrets the North American substitution in the field of Education, the methods which have disappeared and the quality prose used for ideas.
\end{abstract}

key words: The Discovery of America, the Conquest, Chroniclers, Travel Writings, Intellectuals, History of Ideas, Fashions, Comparism, Comparativism

\section{INTRODUCCIÓN. FRANCIA, ¿CUÁL DE ELLAS?}

Francia es uno de nuestros más constantes afectos, al punto de provocar una querella cariñosa con otras viejas querencias, la cultura española por ejemplo, la norteamericana, acaso otras culturas europeas como la alemana, a donde más de uno de nuestros filósofos profesionales (por mucho que esa expresión tenga algún sentido) ha ido a buscar inspiración y escuela. No, no es que tome la pluma para sostener que «la cultura latina» exista, esa ilusión culturalista que marcará la generación del 900 peruana y gran parte de los miembros de la del Centenario (de los dos García Calderón a Porras y a Luis Alberto Sánchez) sino que, preguntándonos porque los escritores de una cultura tan particular como la del Perú, desde nuestros eruditos coloniales y sabios de nuestra escueta Ilustración en el siglo XVIII, a los héroes de la aventura contemporánea, de César Vallejo a Mariátegui, y Scorza y Mario Vargas Llosa, unos y otros, han sido tan tentados de combinar, aunque de manera diversa, la aldea peruana con esa otra cosa, externa sin duda, pero entrañable que viene a ser la tentación francesa.

Simplemente, y conviene decirlo desde las primeras líneas, porque Francia ha encarnado no solo para peruanos sino en la ancha Sudamérica del espíritu, lo que el venezolano Mariano Picón Salas Ilamara «un insinuante universalismo» (Picón Salas, 1983). Admiramos, por cierto, la gran literatura «del siglo de Oro» español, Lope o Quevedo, «tan nuestro como el de ellos» (Octavio Paz). Y a la vez, cosas de la versatilidad de los latinoamericanos que somos, la ciencia y la filosofía alemana, de Kant a Habermas, pasando por el oscuro Heidegger (pero al fin de cuentas, tan importante, el tardío Heidegger por su resistencia a un mundo de la técnica bajo un americanismo sin alma ni riberas), Francia, al lado de otras naciones culturales, se nos antoja, con derecho o en la ilusión cultural, un equilibrio entre razón y pasión, entre provincianismo y desatado universalismo, entre arrebatos de cerrada lógica como la escuela de Port Royal y las penumbras lúcidas del surrealismo de Breton, y en materia de instituciones y vida política, entre el orden de la Quinta República y los sacudones del mayo de 1968. Como si ese pueblo y nación ostentaran la envidiable receta capaz de combinar en sucesivos momentos de su vida colectiva, la tradición y la innovación, las sólidas instituciones bonapartistas (Código civil, la Legión de Honor y la Comedia francesa) y el reclamo de la calle. Francia, continuidad y ruptura, tan necesarias la una como la otra. No, no es la armonía lo que por mi parte admiro en Francia, 
y en discrepancia con mis mayores, sino sus saludables espasmos. Y esa manera de volver a lo mismo, sin que lo mismo sea lo de antes. ¿Cómo se llama eso, ese arte de cambiar y permanecer igual a sí mismo? Acaso simplemente civilización. Pero puestos a confesarnos, debo añadir, en materia de parecidos y diferencias, en materia de conquistas culturales, es posible que no nos atraiga precisamente la Francia del terruño, al fin y al cabo uno es afrancesado pero no francés. Nos fascina lo contrario, desde la aventura transatlántica, tiempos de los marinos de la Saint-Malo en el XVII a Rosamel y Du Petit Thouars, los grandes viajeros como D'Orbigny y Wiener, gente de exploraciones que se continua con los etnólogos del siglo XX. Viajeros a modernos científicos, siempre visitantes atraídos desde hace siglos por nuestra singularidad, la de nuestros talentos pero también las de nuestras costumbres, las que supieron observar, describir y a menudo criticar con sorna y piedad, en páginas de sociología de ultramar que pudo haber firmado o envidiado, el mismo señor de Voltaire (Macera, 1999).

En revancha, no amamos necesariamente a André Maurois, y la saga familiar de los «Thibault» nos dejan fríos, y ese narrador francés tan pegado a sus viñedos llamado François Mauriac cuyos relatos nos ponen al alcance algo como los anales de una sociedad burdolesa fuera de nuestras preocupaciones. Continente el nuestro, de grandes ciudades donde arde la gente que todavía lee por preocupaciones muy distantes a esas horas provincianas que pueblan, a veces, lo mejor de la literatura francesa, su arte y su cine. No es por azar que la otra Francia, la de la aventura, la del riesgo y la transfiguración, es decir André Malraux, en cambio, nunca dejó de interesarnos. Francia alterna, lo sabemos, la hora provinciana y la cosmopolita, a veces hacen solo una, y es entonces Sartre, novelista o filósofo, y abrazamos todo el sartrismo, incluso en sus caprichos y errores parisinos. Y Camus, que nos conmueve particularmente, ese hijo del África del norte, del sol, de la cashba, que amaba el fútbol y las calientes playas, y que «si había que elegir entre una ideología y la madre, preferiría esta última». Lo amamos porque lo sentimos cercano, no pudo hacer todos sus estudios por falta de medios (como tantos otros escritores latinoamericanos) y subió a París, como tantos otros, venidos no solamente de la provincia francesa como monsieur de Rastignac sino de México, Buenos Aires o de Lima, para encontrar, allá, la gloria. ¿Cúal es finalmente el país de Camus, ese sudamericano? Todos o ninguno, como no lo es en Malraux, acaso el arte, en el último, el del «Museo imaginario», cuando la mirada occidental rescata la obra de otras civilizaciones creativas pero a la vez incapaces de admirarse a sí mismas. Es verdad, el siglo que Malraux atraviesa, como dice el lugar común de sus biógrafos, es también el nuestro, el de la desgracia de la historia y el asombro de la fraternidad de los hombres en situaciones límites, revoluciones en China, guerra civil española, resistencia. ¿Quieren saber el secreto de por qué nos interesa Sartre, Camus y Bernanos, cuyos «cementerios bajo la luna» son el otro nombre para idénticas desolaciones nuestras? Porque ellos habitan además de su propia lengua y cultura, el territorio del tiempo y de la historia, comunes a todos los hombres. Es entonces, en la gran piedad de ser como todos es que Francia siempre nos ha parecido grande, más grande que sí misma, con «El discurso del método» hecho para que todo hombre y no solo el francés razone. Y es también el pueblo que escribe «La declaración de los Derechos del Hombre», no el del hombre y ciudadano francés, sino el del Hombre a secas. Una propuesta universalista que no tuvo, por ejemplo, la admirable por otras razones, constitución americana de 1787. Otra puerta de ingreso a la modernidad, sin duda, pero otra. Todavía la empujan gente de la inmigración, tras la green, varios millones de nuestros adelantados en el vientre mismo del Imperio, «hispanos» y «latinos» por doquier, hoy en New York o en Arkansas, sangre de nuestra sangre, marcháronse de nuestras tierras, acaso para siempre, hacia la América del mercado y las posibilidades, hartos de nuestros enredos y bizantinismos.

\section{LA AVENTURA FRANCESA. ANTE LA ESFINGE DEL PERÚ}

Nuestro país, que por momentos nos parece atroz y otros el único lugar donde podemos realmente vivir (y Mario Vargas Llosa ha dicho claramente las relaciones de amor y odio que lo marcan ante el Perú) admira a otros pueblos, y a la vez, es sujeto de predilección. Sí pues, siempre hubo una 
suerte de curiosidad, de mutua simpatía entre Francia, si se me permite esta amable abstracción, y el Perú, por lo mismo, concepto no menos amplio y no menos conmovedor. Una corriente alterna hubiese dicho el mexicano Octavio Paz, que llevaba la friolera de algunos siglos. Es hora de preguntarnos no por los motivos de tan alargada pasión, desde el XVI, y acaso menos por los aparentes motivos y más bien, como en esos matrimonios del antiguo Régimen, por las prosaicas razones de un mariage de raison.

No fue el Perú el primer asombro europeo. Lo precedieron las noticias sobre los Códices o libros de los mayas, y de mixtecos y nahuas, y las cifras y calendarios mexicanos, o la ruta de las canoas caribeñas tras el primer journal del mismo Colón, o la traducción de una carta de Américo Vespucci del latín, o las apostillas de un desconocido Waldsemuller y el erudito error que le cambia de nombre al nuevo mundo, en ese mapa de 1507, en donde no asoma ni Quetzalcoatl, el dios humano civilizador, ni la sorpresa, más tarde, el Perú, «otra China», el archipiélago vertical andino, y en su centro, ciudad ombligo, el Cuzco. No estamos, ni mexicanos ni peruanos, no todavía, ni en el mapamundi de Martin Behaim llamado globo de Nuremberg, de 1492, ni en el mapa de Juan de la Cosa de 1500. Las Indias Occidentales se vuelven maravilla cuando asoma el penacho de Moctezuma II, y entra el Nuevo Mundo en la codicia de las cortes europeas y en la curiosidad de los humanistas y pensadores. ¿Qué es en efecto, ese vasto otro mundo que han abierto los cuatro viajes del almirante por un Caribe que se pensaba chino o malayo y resultó apenas un archipiélago desconocido, escondiendo treinta años no una sino dos civilizaciones, la azteca y la andina, a la codicia de la Europa cristiana?

¿Cuándo comenzaron a interesar esas tierras del Anahuac mexicano y las altas y al parecer herméticas del Perú, cargadas ambas de ricas minas de plata?

Ciertamente, los grandes descubrimientos, el encuentro brutal entre el viejo y el nuevo mundo tras Vasco de Gama, Magallanes y Colón, primero afectaron el mundo de la erudición y del conocimiento, el del Renacimiento, y con razón. De esos lugares, ni de su gente, frutos y faunas, hablaban ni la biblia ni los clásicos griegos y latinos. Lo de las indias es una puesta en cuestión del principio de autoridad, una puerta abierta a la duda, al libre examen, tanto como los martillazos de Lutero cuando coloca sus 95 objecciones. No es por azar que Maquiavelo es de 1513, y no puede sino recomendar al «Príncipe», una navegación política técnica y fría, a la pequeña semana, digno de un tiempo de repúblicas italianas pequeñas y de grandes incertidumbres. $Y$ que Gargantua sea de 1532, y que Montaigne comience a escribir sus ensayos desde 1580. Las dudas que plantea la novedosa geografía y etnología americanas tienen mucho que ver con la atmósfera de esos tiempos, el lujo de la autonomía del pensamiento ante los dogmas tradicionales. Toda América era una vasta herejía.

Pero, de nuevo ipor qué la instantánea simpatía por el Perú de los vencidos, por el Inca Atahualpa, inmediata a su desgracia? Ese Perú indígena de leyenda y en manos ajenas, de donde se introduce en la economía del capitalismo comercial de la época, un Marañón de oro pillado, robusteciendo la potencia de los Austrias alemanes y españoles. Así, lo de Cajamarca pasa a ser tema de prosaico balance entre potencias europeas. El postincario financiará la Contrarreforma. Es otra pues la lectura de la caída del Imperio incaico visto desde una Europa en llamas. No es un asunto baladí ni ajeno esa captura del Inca Atahualpa en manos de unos aventureros españoles, ciertamente soldados de fortuna e improvisados capitanes, pero que ensancha peligrosamente la ya vasta y opulenta geopolítica del Emperador Carlos V. Hay que entender en ese contexto de agravada política internacional, el ingreso del Perú como noticia a la vida francesa, esto es, ese incunable editado en 1534 en Lyon, Nouvelles certaines des isles du Pérou1, suerte de primer

1 Con el título de Nouvelles certaines des Isles du Pérou se publica en 1534 y en Lyon un pequeño opúsculo cuyo ejemplar único se halla hoy en el British Museum. Desde su aparición, gozó de la acogida de los historiadores que la llamaron «La Relation française de la conquête du Pérou». Reproducimos a continuación algo del prolongado subtitulado que precisa en la edición original su valor:

«S'ensuyvent les lettres de Francoys Pizarro gouverneur du riche pays et province nommee le Pérou faisant mention des merveilleuses choses tant veuez par ses propres yeux que par lettres à lui envoyees par ceulx qu'au mesme 
informe de un anónimo corresponsal de guerra, que daba cuenta como un imperio nativo caía en manos de España, mientras reproducían y divulgaban la lista de tesoros arrebatados al templo del Coricancha y llevados por los galeones hasta Sevilla. La Europa a la que llega esas Nouvelles con la desgracia de un emperador peruano es la de las guerras de religión en cada estado europeo, que se dobla en guerra sin cuartel entre imperios y nacientes sociedades nacionales, la monarquía inglesa, la monarquía francesa, anomalías nacionales en un mundo de imperios avasalladores. El Otomano, el de los Austrias. Y un Papado beligerante, sacudido por la Reforma luterana. Coincidencia, pero cuando un desconocido hidalgo llamado Hernán Cortes toma la capital de los aztecas es también el tiempo de la bula papal Exsurge domine que excomulga a Lutero y sus 41 proposiciones. Cuando al Perú llega en 1572 don Francisco de Toledo, el enérgico inventor de «un Estado nuevo sucesor de los incas» (Bradin, 1991: 160). Ese hombre y su círculo de confianza, serán los conceptores de un blando despotismo jerárquico que incluye kurakas y que funcionará tres largos siglos. No vienen de la nada, tienen a sus espaldas un viento teológico a favor, el del Concilio de Trento (1545-1563). La conquista material se doblará, como sabemos, en conquista espiritual. Nada puede eximir a la Iglesia católica de sus responsabilidades históricas.

Así, volviendo a la visión del mundo y a la disposición francesa para ligar esos hechos americanos a su propio destino, ¿cómo no considerar, en esa primera globalización del XVI, que la suerte de ese desgraciado rey de los incas no estaba lejos de lo que esperaban a los reinos musulmanes, y la suerte del Cuzco o de México-Tenochtitlán, lo que podía ocurrir no solo en las urbes otomanas, en los sultanatos como Fés o Bagdad, sino en las alzadas villas alemanas o flamencas, para mayor gloria del César hispano? ¿Y no era acaso aquella una cartografía transatlántica, «católica y universal» como gustaban decir las monedas y la tapicería real de Carlos V, una nueva Roma cristiana que reina en gran parte del mundo, uniendo en la telaraña de los administradores españoles y sus soldados a pueblos enteros, desde las tierras de tupis y de incas hasta ciudades alemanas, y herencias burguiñonas, italianas y castellanas, en Carlos $\mathrm{V}$, señor de varias herencias y treinta coronas? En Francia, no debe haber sido muy difícil establecer el vínculo entre el vencedor en Cajamarca, en 1532, por muy remoto que fuese el lugar de esa hazaña de los Conquistadores, con la captura de Francisco I en la batalla de Pavia, en 1525, es decir, siete años antes. No eran solamente los memorialistas de corte los que tenían recuerdo de ese hecho sino todo el mundo, lucido el acontecimiento en tapices y pinturas. La Francia de las primeras noticias del Perú es la contemporánea de las desgracias de un monarca francés vencido también por la misma ambición imperial, la misma ortodoxia y el mismo desconocimiento de los particularismos, a uno y otro lado del Océano. La suerte de ambos monarcas, el francés y el indio, y la de ambos pueblos, no fue la misma, claro está.

Francia será el escenario del acrecentamiento del poder real — pese al poder de las grandes casas de Orléans, de los Bourbon, Valois, Armagnac - mientras crece el impuesto real, la población y la conciencia de sí. Por aquel entonces, no se nacía francés, se aprendía a serlo. El soberano es la pieza maestra, observa, sin ironía, Maquiavelo. Mientras lo peruano políticamente se demora, en la larga siesta colonial. En resumidas cuentas, el sino fatídico del último emperador peruano en Cajamarca, paradójicamente sirvió para el primer flechazo de amor entre ambas culturas, ambos procesos históricos. Ambos pueblos.

Desde entonces, en el correr del tiempo, y por siglos, la cultura francesa en manos de eruditos y también de hombres de estado, no dejará de indagar, soñar o intentar conocer el lejano confín llamado Perú.

pays habitent aux quelles sont contenues plusieurs choses nouvelles tant des richesses inextimables d'or et d'argent et pierres précieuses en cette province trouvees et d'iceluy pays emenées que de plusieurs aultres marchandises et richesses, et ce depuis le temps qu'il monta sur mer jusques à présent».

La obra es, en realidad, una compilación de cartas privadas y de relaciones breves, originarias de Panamá y que no difieren en exceso de la versión de otros cronistas, como Francisco de Xerez, Miguel de Estete, Pedro Pizarro, o Cristóbal de Mena. Su editor sabe, sin embargo, que esos cronistas, por los obstaculos de la lengua, no lograrían comunicar rapidamente, como sí lo hace Les Nouvelles, de los excesos de la soldadesca española en Cajamarca.

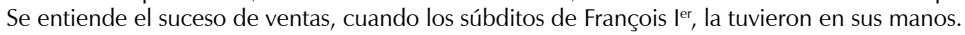


No faltaban razones. La realidad americana, con los nutrientes mexicanos, caribeños y peruanos, había cambiado el mapa político europeo, dándole recursos en metales preciosos a la moneda del imperio de los Austria. Y el trabajo de los indios mitayos fue a despilfarrarse en las guerras contra los príncipes protestantes alemanes. Pero de ese Perú de dominación e infortunio, llegaron diversas cosas concretas y otras aladas, inspiradoras de utopías sociales en la formación de la propia conciencia europea.

Llegaron nuestros embajadores, el dulce maíz, un poco más tarde la coca y la quina, plantas medicinales. Y llegó no solamente la yuca sino la variada papa, que un francés Antoine De Parmentier divulga (1737-1815). Cierto que tarda en obtener carta de ciudadanía. Fueron necesarias los grandes hambrunas de 1830. iLa aventura de la papa! Un producto inventado por el genio indio experimentador y creador anónimo a partir de unas raíces amazónicas en su orígen natural ponzoñosas, planta al comienzo exótica y luego de lo más común, el kartoffen de belgas y alemanes, pero ya Bonaparte la consumía a lo largo de sus campañas, porque al decir de su cocinero en jefe, «era el producto más corriente en los campos europeos». El apotecario Parmentier fue uno más seducido por la novedad de lo peruano, tanto como en las letras, madame Françoise de Graffigny, y sus Lettres d'une péruvienne (1747) en el estilo epistolar tan frecuentado en el Antiguo Régimen, quien, dicho sea de paso, no puso nunca los pies ni en Perú ni en las Indias, ni se alejó demasiado de su castillo de Cirey, pero lo suficiente como para visitar a Voltaire, de quien se ocupa en cartas indiscretas, entre las 2500 que escribiera, como para llenar los 14 volúmenes de su legado (Graffiny, 2005). Tampoco era alguna fidedigna reconstrucción histórico-teatral Los Incas de Marmontel, ni menos, la farsa romántica de Mérimée sobre La Carroza del Santo Sacramento, un ensueño de romanticismo, donde Mérimée después de haber explorado y explotado las posibilidades de la vitalidad femenina en Carmen, la española, va tras otra figura literaria, siempre la mujer, personaje propicio para la revuelta romántica de los escritores varones contra el orden clásico establecido, y que no será ni la gitana ni la española sino la liménienne, la limeña. A eso se sumaron los viajeros franceses, en el XIX. Curiosamente, en Tahiti, vuelto francés, surge otro mito feminista, la vahine, otra alegoría de la libertad sexual.

No solo pues metales y nuevos alimentos. Llegaban de allende los mares, otra geografía. Menos mal que el Renacimiento ya preparaba a los europeos a la sorpresa de los nuevos descubrimientos geográficos, la sorpresa de los cielos con Galileo y la sorpresa de otros pueblos, otras religiones, otras culturas cuando comienzan a llover textos de crnistas y viajeros, una avalancha de nuevas informaciones para la cual la cultura clásica, fundada en el paradigma bíblico y grecoromano, no estaba preparada. No es exagerado decir que un mundo perdido y súbitamente recuperado, el de Indias, apresura la modernidad por un cuestionamiento venido de las antípodas. «Me muero de frío», dice irónicamente el padre Acosta en sus crónicas, a poca distancia de Quito, «pues según las autoridades, estando tan cerca del Trópico, debería arderme de calor».

La curiosidad por el Nuevo Mundo no se apaga del XVI al XVIII, y cuando los nuevos soberanos, los Borbones, abren los puertos indianos a los visitantes, en 1735, tres dignatarios de la Académie royale de Paris, entre ellos De La Condamine, visitan el Perú para medir el meridiano terrestre. Época de expediciones, la cierra brillantemente Alexandre de Humboldt, a quien por alemán y por escribir en francés conviene incluir, al «verdadero descubridor de América» como le llaman sus actuales biógrafos, que nos lega una suma de conocimientos tanto naturales como sociales; fino observador, su valor crece con el tiempo. No terminamos de leer a Humboldt.

En suma, desde el XVI había llegado a Francia y por la vía de los intercambios entre humanistas, a toda Europa, la noticia entre inquietante y alarmante de una otra historia. Ese no era el mundo conocido, ni africano, ni musulman ni chino. ¿Qué eran esos pueblos, en particular el azteca y el inca, que al margen del mundo conocido, se habían alzado hasta la civilización?

El tema de la admiración por los vencidos implicaba una revaloración de los mismos, y en consecuencia, se prestó a debate y controversia a la vez teológica y política. ¿Acaso no dice 
el segundo Cieza2 que antes de la conquista cristiana, que por cierto no discute, es el horror y el estado de barbarie la condición de los indios, antes del régimen de los incas. Con lo cual debilita la tesis de quienes veían a los soberanos cuzqueños como tiranos, y en consecuencia, se justificaría la dominación con obispos, corregidores y encomenderos. Es decir, la Conquista y colonización. A Cieza hay que leerlo con atención, cercano a las Casas en esa demanda increíble de restitución de poder para los «señores legitimos del Perú», sino a los desaparecidos Incas, al menos los kurakas. Dice Cieza:

«No es pequeño dolor que, siendo aquellos Incas gentiles e idolatros, tuviesen orden para saber gobernar y conservar tierras tan largas, y nosotros, siendo cristianos, hayamos destruido tantos reinos...»

Un debate inmenso se abre entonces, sobre la naturaleza de esas gentes y sus sociedades.

Entre tanto, el caballero de Montaigne, atrincherado contra las tonterías y fanatismos de su tiempo en su casa como un castillo de ideas, deja por un momento de ocuparse de Sócrates y Plutarco, o de los habitantes de Tracia, recojiendo la información venida de Indias:

«los indios en el Perú hallan las orejas más grandes entre las más bellas». (XII, Apología de Raimundo Sebond)

Cita mucho Montaigne los temas americanos, hojea ese mundo, no lo estudia, confiesa, pero funda de esa manera casi negligente un arte del razonar con esceptismo, que le debemos, casi diría, precursor «del relativismo cultural». Grandes dudas se insertan en la conciencia europea tras la visión de un imperio de los incas de cronistas y de la obra del Inca Garcilaso. O la prédica del padre Las Casas. Y la controversia en Valladolid sobre la validez o no de la esclavitud india, y la obra de los pensadores cristianos españoles del Seiscientos, y de la bondad natural del hombre, de la igualdad de los hombres para comenzar ante la fe. Y más tarde, sin duda, a la idea de un contrato social en Rousseau. No insistiré, sobre la huella del imperio Inca en el imaginario de las elites francesas; se han escrito sólidas tesis sorbonianas.

La idea de utopía se ancla a la vez en el pasado, en Platón, y con tenacidad, vista la prosperidad y el saber de ese pueblo maya y azteca que interrumpe la Conquista -0 la perduración de los ayllus y comunidades en las tierras elevadas andinas - tras la literatura de viajeros y visitantes, mucho antes que los modernos étnologos. Campanella, Bacon, Moro, se bañaron en esas fuentes, al punto que hoy nos es imposible separar esa literatura de sueño y viaje del XVI al XVIII, de las utopias sociales del siglo XIX y XX. Ciertamente, las utopías pueden haberse encarenado como viejos navios en puertos de arribo totalitarios, pero late por debajo de los pueblos ese sueño de fraternidad humana, como un fuego de volcanes, imperecedero. ¿Puede sólo el sueño de la razón capitalista conducir el mundo? ¿Sin una promesa, un mito, un atisbo de otro estado de cosas, otra humanidad? Cuestión que planteo y de inmediato abandono. No para estas páginas.

En la actitud francesa, en el tiempo, cambiaba la agenda no la curiosidad. Al explorador tras la medición de la altitud, como el citado De La Condamine, le sigue otros, marinos como Feuillée, Frézier, Jussie [sic] o Dombey, no vienen solamente a abrir el comercio, o las rutas militares, viejos lobos de mar o almirantes, sino a observar, fisgonear, mirar. Nos interesan, se detienen menos en las ruinas y más entre las gentes, sus costumbres. Estoy pensando en D'Orbigny, en de Sartiges, y en particular en Radiguet. Este último describe el Perú independiente, reprochándole su retardo.

«iHa respondido seriamente la América del Sur a las esperanzas de Europa? Treinta años han transcurrido [agrega] desde la emancipación de las colonias del yugo de España, y

2 Cieza, el segundo. A Cieza le conocemos, por una parte por Crónica del Perú (1552) la cual logra publicar en vida la primera parte. En ella ya existen juicios y observaciones suyas de elogio de las leyes de los incas. Pero en la segunda parte de su obra, se presenta al Estado Inca como un modelo. Una fuente segura para ambas partes es Pedro Cieza de León, La crónica del Perú, con estudio de Julio le Riverand Brussone (ed.) Crónicas de la conquista del Perú (México, s.f.). 
por todas partes ha reinado la anarquía, y ha aumentado el desorden. México, Perú, La Plata, Ecuador y Bolivia, están siempre minados por esas pequeñas revoluciones del interior llamadas pronunciamientos...»3.

«Las pequeñas revoluciones...». Se ha creído reducir la riqueza de estos testigos a amenas crónicas de circunstancia, literatura de viaje, descripciones de costumbres, y es cierto que el mismo Radiguet halla a limeños y limeñas, «los parisienses de la América del sur». Y si bien el capitán de navio Auguste-Nicolas Vaillant, en un alto a la vuelta al mundo en la expedición de La Bonite que dirige, se da tiempo para presenciar la fiesta de Amancaes, también es verdad que a un marino bien bragrado como a Amadée De Frézier (uno de los primeros, por 1713) lo había ya escandalizado el lujo y derroche de las damas limeñas, y que a Humboldt encuentra deplorable la manía del juego en las clases altas «y lo lejos que estaba Lima del Perú». Así, en el siglo XIX, la mirada francesa se detiene, con Alcide d'Orbigny en la descripción de una familia burguesa de Lima, o con Borget en lo que son sus calles. ¿Simple literatura de voyages? Sin duda el romanticismo tiñe muchas de esas páginas con amenidades y cosas curiosas, pero por igual hay descripciones sin clemencia de minas, haciendas, subprefectos y situaciones penosas, que los viajeros, en particular los franceses, no callan. Más de uno asiste a un fusilamiento. Aquel nos dice como era un «pronunciamiento», con el inevitable discurso patriótica del prohombre de turno en plena calle, cuentan acerca del escepticismo y la guasa del vecindario, mientras circulan las tapadas, maestras de intrigas, de psicosociales estilo decimonónico, entre la multitud. Cuadros de sociología, que digo, de antropología política, de una inquietante actualidad, y que esperan otra interpretación.

En un discurso en el Senado (en 1958) Porras Barrenechea advierte como la aventura de los viajeros ayuda a descubrir geográficamente el Perú al mundo y «a calar en nuestra realidad social, en las características psicológicas del hombre peruano» (Porras Barrenechea, 1999: 239 ss). Porras no lo dice, pero lo agrego yo, uno de sus díscipulos. La crítica a las costumbres en los viajeros, por lo general inmersos en las grandes polémicas sobre la libertad y las revoluciones europeas, su sensibilidad social, prepara y antecede lo que será el despertar de nuestra propia conciencia en escritores, poetas, pensadores, ensayistas y políticos. Ya el liberalismo y el romanticismo había abierto una trocha, ahí está Ricardo Palma. Luego viene Manuel González Prada, el de la acerva crítica, y Víctor Haya, José Carlos Mariátegui, Jorge Basadre, Luis Alberto Sánchez, Luis E. Valcarcel, José Antonio Encinas, Victor Andrés Belaúnde, el propio Raúl Porras. Son muchos, una pléyade. La sensibilidad de los viajeros prepara el esfuerzo de introspección de varias generaciones de ensayistas. Son nuestros moralistas, a la manera de los franceses del XVIII (Neira, 1996)4.

\section{LA AVENTURA PERUANA. LA PROLONGADA LECCIÓN DEL ORDEN Y LA CLARIDAD, A LA FRANCESA}

Tres grandes momentos se distinguen nítidamente en la asimilación peruana de la cultura francesa. Es visible, hasta el punto de ser obvio, un primer momento de afrancesamiento que no dura décadas sino, cómodamente, parte del XVIII, el siglo XIX por entero, y algo del inicio del siglo XX. En los años 1930 se produce un punto de quiebre, hacia la cultura norteamericana, explicarlo requiere un libro entero. El segundo momento, que coincide con una relativa tolerancia a la crítica de los intelectuales, y al renovado interés de los peruanistas franceses por el Perú, son los años 1970. El tercer momento es, sin duda alguna, los años actuales, el ahora, otra problemática, la presente: los efectos de la mundialización. Estos grandes ejes que aquí trazo, ni son perfectos,

3 Max Radiguet: oficial de la marina de guerra francesa, escribe un libro a partir de sus impresiones de viaje tras recorrer la América del Sur entre 1840 y 1850. El libro se titula Souvenirs de l'Amérique espagnole (1856). Los textos a los que aludimos han sido tomados de Macera, Viajeros franceses (1999: 253-257). Existe traducción completa al castellano.

4 En materia de la endemia de la corrupción, conviene consultar El mal peruano, 1990-2001, Sidea, 2001. 
ni explica convergencias y distancias disciplinarias, la asimilación de cada quien, ni tampoco voy a agotar en este sumario recorrido lo que al esbozarse en estas líneas, apenas resulta un plan de trabajo posible. Ya veremos, los estudios culturales en el Perú de esta naturaleza están en pañales.

Pero otra cosa puedo aquí abordar, la dimensión oculta de estos cambios. El porque de una cultura francesa con cambios periódos, como el movimiento de los astros, de acercamiento o de lejanía, de apogeos y perigeos. No es un hecho simple, ni se agota en la puerilidad de las escuelas, las preferencias ideológicas o si hay bolsas de estudio para viajar a Europa.

Jacques Soustelle, el admirable mexicanista autor de Les quatre soleils, expresa la problemática de estas líneas en una frase que no resisto en citar, «toda civilización no es sino el sueño de una otra» (Soustelle, 1967: $215 \mathrm{ss})^{5}$. Acaso el concepto de rêve tenga que traducirse por el deseo, el anhelo de ese otro, al que no se pertenece pero se toma como espejo o modelo. Seré claro, la sociedad peruana, entendamonos, la elite limeña, sueña durante el siglo XIX con la lección civilizadora francesa. Pongo este pórtico al ingreso a la inevitable mención de las modas literarias y en general de la vida social de la influencia francesa, pero pórtico que advierte que esas modas, es asunto menos mundano y frívolo de lo que se pretende. Fue una disposición a acatar lo francés en ese largo siglo en el que se hicieron muchas cosas, salvo otras, como construir la nación (Deler \& Saint-Geours, 1986).

Como siempre, se optó por el parecer y no por el ser. No había que parecer una nación moderna, imitando lo superficial, había que construir precisamente lo que hace de Francia un caso ejemplar, desde sus ferrocarriles, instituciones y escuelas decimonónicas. Es como si el discurso sobre «la nación» de Renan hubiese sido atendido por unos cuantos incomprendidos, como Manuel González Prada. En cambio, dejando de lado lo trabajoso, el Estado, las leyes, aquel fue un siglo peruano de galicismos, crinolinas en los trajes de las elegantes, dramas de Dumas en los teatros, periódicos o gacetas que replicaban los arrestos de los Guinet y los Benjamin Constant criollos. Y sin duda don Felipe Pardo, pese a su voluntario alejamiento en España ante el mal gusto de «la republiqueta», estaba finalmente más cerca de «la vena traviesa de Berenger», como afirma Raúl Porras en el citado discurso suyo. Es cierto, también, que Mercedes Cabello de Carbonera seguía el molde narrativo del naturalismo de Émile Zola, mientras se leía a Jules Verne y a Pierre Loti, y Riva-Agüero hacia lo propio con Taine y Fustel de Coulanges.

Dejando de lado la frivolidad, desde el acojo de las ciencias y el conocimiento, no fue aquella una imitación del todo desdeñable. El Perú como en otras ocasiones, parece acercarse a un salto hacia la modernidad, para luego tomar caminos inesperados y por lo general, extraños, catastróficos. Por aquel entonces, a comienzos del siglo XX, en filosofía, el positivismo tiene su hora, no tan intensa como en México o Brasil, pero reuniendo, si seguimos en la materia a Augusto Salazar Bondy, un doble movimiento, uno de tipo extrauniversitario, que lo ocupa Manuel González Prada, y otro universitario, dice Salazar Bondy (Salazar Bondy, 1965)6 donde encaja la obra y la acción pedagógica y política de Javier Prado, Jorge Polar, Joaquín Capelo, Carlos Lisson, Mariano H. Cornejo, Manuel Vicente Villarán.

Ahora bien, a diferencia de muchos otros historiadores de nuestra evolución cultural, discrepo en el denigramiento de esa corriente positivista. Cierto, era un saber seco y frío, de ingenieros de camino y gente que soñaba con resolver cándidamente los males nacionales irrigando desiertos costeños sin cambiar las formas de producción, o traer inmigrantes al despreciar al indio, y ese positivismo no del todo Comtiano, mezclado al de Spencer y otros, era una ideología de la dominación. Pero bueno, con ellos vino, pese a lo dicho, los primeros estudios sociológicos, la preocupación por la ciencia, el derecho y la moral, la educación y el progreso. Hubo una crítica de la metafísica, y precisamente, el libro de Augusto agrupa la reacción de la generación

5 Sé que Soustelle aparece como «superado», estragos de la moda estructuralista. Pero ese libro, me parece uno de los más bellos textos de la antropología, tanto como Tristes Tropiques de Claude Lévi-Strauss.

6 ¿Para cuándo una reedición? 
siguiente, de Deustua a los García Calderón, como espiritualista, estética, o sea, «una nueva metafísica». Abriendo las puertas a posteriores irracionalismos.

Por un rato, este país caminó. Contrariamente a lo que se sostiene, la debacle de la guerra del Pacífico sacó a la clase rica de sus hábitos rentistas, descubrieron los hacendados azucareros y algodoneros las ventajas de la coyuntura y el mercado exterior. Lo cierto es que la economía peruana entra en una fase increíble de expansión desde la reforma Piérola de la moneda en 1895, hasta la gran crisis mundial de 1929. En ese lapso, el país tiene su primera edad de industrialización, de bancos y compañías privadas, y en materia de cultura, se puebla de instituciones calcadas sobre las francesas. Escuelas normales para formar pedagogos para la instrucción primaria y secundaria, suerte de «húsares negros» como la IIIra República de Gambetta, y no tiene, por entonces, doctores de ingeniería sino Escuela de ingenieros. Y grandes Escuelas. Politécnicos. Si eso hubiese seguido, otro gallo nos cantará.

Ahora bien, cabe preguntarse qué se olvidaron de hacer en el afrancesamiento decimonónico las clases dominantes, antes de la Guerra del Pacifico. Y de qué se volvieron a olvidar en el período de fastos exportadores entre 1895 y 1930, bajo una fase de ciclo Kondratiev favorable, diríamos, aceptando la lección de la historia económica-social a lo Braudel, una larga duración. Se olvidaron en el siglo XIX de resolver el problema indígena. En el Perú ni siquiera una revolución liberal de reforma por la vía legal de las amortizaciones, como en el México de Benito Juárez. Ese país donde la masa de indios paupérrimos que luchaban por el general Perú contra el general Chile, no podía ganar la guerra. Con el verdadero Perú, como lo dirá González Prada en su discurso del Politeama en 1888, fuera de la nación. ¿Y de qué se volvieron a olvidar los clubs políticos (el sufragio universal llega en 1931) en las prósperas décadas de comienzos del siglo? De lo mismo, de los indios paupérrimos en los latifundios con el agravante que al tema de la no-nación se agregan, pronto, las masas.

No sigamos, vino desde los años 1930 la realidad de un país escindido, y el bloqueo del aprismo y los comunistas por una larga guerra civil, 1931-1956, que callan hipócritamente nuestros textos escolares. El Perú perdió dos veces el tiempo. En el XIX, el momento de llevar adelante una revolución industrial burguesa (se podía, hay estudios). En el XX, de un Estado moderno (también se podía, prefirieron llamar a los dictadores civiles y militares).

¿Pero cómo olvidar a Louis Baudin, profesor de derecho en Dijon, cuya obra sobre la economía y la sociedad inca hiciera soñar a generaciones de peruanos? En efecto, El Imperio Socialista de los Incas es de 1928. El mismo año en que se edita Los siete ensayos de interpretación de la realidad peruana de José Carlos Mariátegui. La idea misma de utopía y de Estado Inca se reúnen. Pero eran horas aciagas, los terribles años 1930 y 1940 en América del sur y en Europa, y aún así no faltaron los grandes visitantes franceses. El antropólogo Rivet fue un gran amigo de los indios y repartió su tiempo y su vida entre Perú y Ecuador donde se casa con ecuatoriana, y luego vuelve a Francia, funda el Musée de L'Homme, sabio y hombre de izquierda, uno de los tempranos fundadores de la liga francesa por los derechos del hombre y del ciudadano.

El segundo momento — en materia de hora francesa— son los años 1960. Sin embargo, conviene señalar que en ese segundo momento algo estaba adquirido, «un capital simbólico» como dirá, más tarde, Pierre Bourdieu. La inteligencia peruana ya había hecho la cuenta de los fracasos de su historia, Jorge Basadre había enumerado los «momentos perdidos», y así, tras decenios de reflexión y lucha social, el desvelo ideológico se combina al trabajo de campo, y esperan de pie firme a los peruanistas franceses, una legión de investigadores peruanos. Era aquel un momento optimista. Se había aplacado la fiebre persecutoria, Haya de la Torre podía dormir en casa, la derecha siempre estaba fuerte pero en la esfera económica y social, habían perdido el combate intelectual. Como se puede apreciar, esas victorias, más en cultura, son efímeras si no las acompañan grandes reformas, que no ocurrieron. En fin, corrían los años 1960 y 1970, y con ellos, una gran ilusión de cambio social y el inicio también de muchos trabajos de envergadura en los investigadores peruanos, vinculados a los mencionados (José Matos Mar, Julio Cótler, Alberto Escobar, entre muchos). 
Hablando del aporte francés, es de esos años la repetida visita de trabajo en el Perú del antropólogo Henri Favre $(1973 ; 1996)^{7}$. Y es de ese momento sin duda privilegiado de la «recherche» de peruanistas franceses, los trabajos de Nathan Wachtel, su Vision des vaincus (1971)8, sus métodos combinatorios de etnohistoria, el intento sin duda logrado de arrancar la lectura de la historia a la historia misma y apoyándose en la memoria colectiva, que recupera en el terreno de las fiestas y danzas y mitos vivientes, arrancar la comprensión de la evolución de la sociedad peruana secular a una visión eurocentrista. Wachtel descentra precisamente la lectura del Perú y la recoloca en el imaginario indio, en hábitos mentales que han llegado a nuestros días, y que no han terminado de decir su última palabra.

En los estudios culturales sobre el Perú, del que el presente es apenas un esbozo, en la revisión de los posicionamientos, en la producción de campos culturales y disciplinarios, nos hallamos ante una segunda evidencia, los años sesenta, la sociedad peruana como terreno de exploración y reflexión de hombres de ciencia social de la talla de François Bourricaud, los geógrafos Olivier Dollfus y Claude Colin Delavaud9. No cito sino los casos más notorios. Hay una investigación sobre el Perú antes y después de esa ola de sabios franceses. Los heredan, de alguna manera, hasta nuestros días, Bernard Lavallé, Carmen Bernand, Yves Saint-Geours.

Sin embargo, el eclipse de la influencia francesa no es sencillo de explicar, pues, para comenzar, mientras se establecían metodologías pueriles en las aulas que dicen inspirarse en el modelo norteamericano (lo cual no es cierto, no tenemos colleges, es decir, una etapa transicional de la secundaria a la enseñanza superior) en realidad la huella francesa permaneció en los espíritus. Con notoria maestría. Me explico. ¿Quién no admira la prosa clara de José Carlos Mariátegui, la elegancia de los textos del historiador Raúl Porras, la facilidad de scholar de Luis Alberto Sánchez? Pues bien, el día que entremos en las entrañas de esa prosa argumentativa —que tiene, insisto, un carácter generacional- y no solamente sobre los contenidos sino sobre los procedimientos lógicos y expositivos, se entenderá lo que después de estas líneas, espero, resulte obvio y evidente. La gran época de los pensadores peruanos, de 1900 a la generación del Centenario, los padres fundadores de todas las corrientes ideológicas y de pensamiento del Perú contemporáneo, corresponde a un arte de la disertación, a un método de exposición de ideas que no es natural, ni viene del talento. Sino de la escuela. De un cierto tipo de entrenamiento en el arte de argumentar en prosa escrita o en lección oral que muchos de nuestros padres fundadores no aprendieron en las aulas universitarias sino mucho antes, en escuelas como la Recoleta, de curas franceses. La preocupación por formar en esos métodos a los más jóvenes fue mermando hasta desaparecer. Se salvan de la masacre de inocentes, tal o cual por haber estudiado en el colegio Franco peruano, o algún cerrado por los precios, colegio privado, pero poco, muy pocos. O los que tuvieron la suerte de tener maestros, los formados por Luis Jaime Cisneros, Porras. Pocos, pocos.

La influencia francesa continuó 10 , aunque no en las aulas primarias y secundarias, apenas en las universitarias ganadas, en particular en la enseñanza superior privada, por el prestigio de lo norteamericano. Pero, ¿cómo dejar de tomar en cuenta que la actitud y disposición a la

7 La producción de Henri Favre es notable. Ha publicado sobre La Hacienda en el Perú (1967). Suele trabajar sobre México. Una contribución más ambiciosa sobre el conjunto de países latinoamericanos es su libro: L'Amérique latine (1998).

8 Un clásico, una obra maestra.

9 De Olivier Dollfus, aparte la tesis, le conocemos El reto del espacio andino (1981). Luego se fue a estudiar otro mundo no menos complejo que el andino, el del Himalaya. Entre su abundante bibliografía rescato, La mundialización, (1999). En otro de sus libros, Dollfus sostiene una tesis muy interesante, la mundialización se entiende como una red entre grandes polos, megálopolis, no más de una treintena. Cf. L'Espace-monde (1995). De Claude Colin Delavaud, conocemos, entre otras cosas, un Pérou en la colección «Petite Planète (1976). Uno de los mejores de esa serie famosa.

${ }^{10}$ Los trabajos del Instituto Francés de Estudios Andinos, su revista, sus encuentros, la calidad y rigor de sus trabajos, no puedo menos que aprovechar la oportunidad en cuánto me son personalmente útiles, y cuánto los recomiendo a mis alumnos. 
investigación, la crítica social y la producción de una prosa científica de calidad, hablo de unos cuantos, Heraclio Bonilla, Rodrigo Montoya, Manuel Burga, el desaparecido y llorado Alberto Flores Galindo, entre los más jóvenes Luis Tejada, no es explicable sin su pasaje por París, y por la École des Hautes Études en Sciences Sociales? ¿Cómo no tomar en cuenta, en contraparte, las perversiones que se acumularon en los aulas de los años 1980 y 1990 ? Nicolas Lynch 11 ha narrado en que se convirtió el San Marcos de esos años, en manos de los senderistas: desaparición de estudios generales, graduaciones sin necesidad de tesis. El resultado son generaciones enteras a las que no se les ha iniciado en el arte mínimo de hacer una ficha, comprender un texto, disertar o redactar (no escribir, ya decía Sánchez, eso es arte mayor). Simplemente, al saber redactar, es establecer un orden de ideas, es saber pensar. ¿Qué ocurre cuando en una determinada cultura, la argumentación y el discurso político se disocian? ¿Cuando los líderes no leen?

He señalado en otra oportunidad, que el planeta Francia sigue emitiendo sus luces, diseminando unos caminos de la libertad, para evocar a Sartre, que son una lectura herética ante la sajona o americana, con otra lectura e interpretación de lo que pasa en el mundo, tras lo que en París llaman mundialización, y nosotros, como si todos fuéramos empresarios, globalización. Punto de vista, aproximación, acaso sesgada, pero que quiza nos convenga más que la del Imperio. Por mi parte admito que recurro a grandes maestros franceses, a mi gusto, referentes externos de toda actualidad, de perentoria urgencia, no solamente a Alain Touraine o Pierre Bourdieu, conocidos acaso por sus posturas políticas en las aulas peruanas de enseñanza superior, sino a la formidable obra de Edgar Morin, de René Girard. Ambos, me temo, en nuestro medio universitario, ilustres desconocidos. Lamentable. Y sin embargo, violencia y verdad es el gran tema de Girard, asimilado en otras culturas universitarias latinoamericanas. O la propuesta de un nuevo paradigma que de cuenta a la vez del orden y del desorden, con Morin. Es lástima, hace un buen rato que el retorno del discurso filosófico a las ciencias sociales, tensa estas con temas que vinculan ética y sociedad, en una vivaz dialéctica que ya tiene decenios, desde Raymond Aron y Jean-Paul Sartre. Pero, La marche des idées contemporaines, para decirlo con un título de Jacqueline Russ (1994), mi libro de cabecera, no tiene lugar en la agenda limeña de preocupaciones culturales. Un campo académico también lo constituye no tanto lo que elige sino lo que deja de hacer. Es el pecado por omisión del que hablaban los teólogos. Y así, para ir pasándola bien, un corto saber pegadito a la vida común y en el mejor caso empresarial, una vida universitaria sin grandes problematizaciones ${ }^{12}$. Escindidos, no digo ya del primer mundo sino de otras culturas latinoamericanas. Y también de nosotros mismos.

\section{Referencias citadas}

BRADING, D. A., 1991 - Orbe indiano: de la monarquía católica a la república criolla, 14921867, 770 p.; México: Fondo de Cultura Económico.

COLLIN DELAVAUX, C., 1976 - Pérou, 190 p.; París: Le Seuil. Colección «Petite Planète».

DELER, J.-P. \& SAINT-GEOURS, Y., 1986 - Estados y naciones en los Andes. Hacia una historia comparativa: Bolivia - Colombia - Ecuador, 2 volúmenes, 668 p.; Lima: IEP-IFEA.

11 Uno de sus últimos trabajos, El pensamiento arcaico en la educación peruana (2004), tuvo altos tirajes, frecuentes reediciones. Por una razón evidente, la claridad de las tesis y el coraje de decirlas: el portador del arcaismo, a juicio de Lynch, es el sindicato SUTEP. No hubo respuesta de los mismos. En el Perú, el silencio es una arma.

12 El caso mexicano es ejemplar. Antropología urbana de México, antropología sociocultural en el México del Milenio, ipor qué no se invita al Perú, para que el medio universitario los aprecie, a los antropólogos e historiadores mexicanistas? Pienso en Serge Grunzinski, Tzevetan Todorov. Harían un gran bien a la cultura y a las temáticas de investigación en el Perú, aparte de abrir las puertas a un sano comparativismo. Hay unas ciencias sociales peruanas que hace rato que se miran el ombligo. 
DOLLFUS, O., 1981 - El reto del espacio andino, 141 p.; Lima: IEP.

DOLLFUS, O., 1994 - L'Espace-monde, París: Económica.

DOLLFUS, O., 1999 - La mundialización; Barcelona: ediciones Bellaterra. Colección La Biblioteca del Ciudadano.

GRAFFINY, F., 2005 - Lettres d'une Péruvienne; París: Flammarion.

FAVRE, H., COLLIN DELAVAUX, C. \& MATOS MAR, J. (eds.), 1967 - La Hacienda en el Perú, 164 p.; Lima: IEP. Serie Estudios de la sociedad rural 01.

FAVRE, H., 1973 - Les Incas, 126 p.; París: PUF. Colección «Que sais-je?».

FAVRE, H., 1996 - L'Indigénisme, 127 p.; París: PUF. Colección «Que sais-je?».

FAVRE, H., 1998 - L'Amérique latine: un exposé pour comprendre, un essai pour réfléchir, 125 p.; París: Flammarion. Colección Dominos.

LYNCH, N., 1990 - Los jóvenes rojos de San Marcos: el radicalismo universitario de los años setenta (comentarios de Juan Abugattas). Socialismo y participación, 50: 105-107. Número especial.

LYNCH, N., 2004 - El pensamiento arcaico en la educación peruana, 83 p.; Lima: UNMSM Fondo editorial.

MACERA, P., 1999 - Viajeros franceses, siglos XVI-XIX, 432 p.; Lima: Biblioteca Nacional del Perú, Embajada de Francia en el Perú.

NEIRA, H., 1996 - Hacia la tercera mitad: Perú XVI-XX: ensayos de relectura herética, 753 p.; Lima: Sidea.

PICÓN SALAS, M., 1983 - Meditación francesa. In: Viejos y Nuevos Mundos: 337-346; Venezuela: Biblioteca Ayacucho.

PORRAS BARRENECHEA, R. (ed.), 1999 - Parlamentario; Lima: Biblioteca del Congreso del Perú. Editado por Carlota Casalino, revisión Fernando Lecaros.

RADIGUET, M., 1999 [1856] - Souvenirs de l'Amérique espagnole. In: Michel Lévy (ed.): 253257; París.

RUSS, J., 1994 - La marche des idées contemporaines. Un panorama de la modernité, 479 p.; París: Armand Colin.

SALAZAR BONDY, A., 1965 - Ideas en el Perú contemporáneo, 470 p.; Lima: Francisco Moncloa editores. 2 volúmenes.

SOUSTELLE, J., 1967 - Les quatre soleils. Souvenirs et réflexions d'un ethnologue au Mexique, 340 p.; París: Plon. Collección Terre Humaine.

WACHTEL, N., 1971 - La vision des vaincus. Les Indiens du Pérou devant la Conquête espagnole, 1530- 1570, 395 p.; París: Gallimard. 